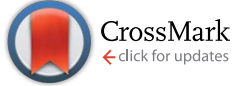

Cite this: RSC Adv., 2017, 7, 12474

Received 25th December 2016 Accepted 6th February 2017

DOI: 10.1039/c6ra28667d

rsc.li/rsc-advances

\section{A promising vanadium sulfide counter electrode for efficient dye-sensitized solar cells}

\begin{abstract}
Xianqing Liu, Gentian Yue* and Haiwu Zheng*
In this study, we demonstrated the synthesis of vanadium sulfide $\left(\mathrm{VS}_{2}\right)$ via an in situ hydrothermal route, which was subsequently employed as a counter electrode (CE) for Pt-free dye-sensitized solar cells (DSSCs) for the first time. It was demonstrated from scanning electron microscopy that the size of $\mathrm{VS}_{2}$ increased with the increasing temperature, and the morphology was also affected by temperature. Extensive electrochemical performance analysis, including cyclic voltammetry, electrochemical impedance, and Tafel polarization, revealed that the $\mathrm{VS}_{2} \mathrm{CE}$ possesses a high electrocatalytic activity for the reduction of triiodide to iodide and a low charge-transfer resistance at the electrolyte/CE interface. The DSSC based on the $V S_{2}$ CE exhibited a conversion efficiency of $6.24 \%$ under an illumination of 100 $\mathrm{mW} \mathrm{cm}^{-2}$ as compared to the DSSC based on the Pt CE.
\end{abstract}

\section{Introduction}

Dye-sensitized solar cells (DSSCs) have received extensive interest due to their facile fabrication, sustainability, low-cost, and environmentally friendliness. ${ }^{1-4}$ The typical structure of a DSSC consists of $\mathrm{TiO}_{2}$ nanocrystallines as the photoanode, dyes, and a platinum (Pt)-coated tin oxide transparent (FTO) substrate as the counter electrode (CE) fabricated with an $\Gamma / I_{3}{ }^{-}$ redox couple liquid electrolyte. ${ }^{5}$ Although $\mathrm{Pt}$ is one of the most selected materials for catalyzing the reduction of $I_{3}{ }^{-}$to $\Gamma$ due to its superior electrocatalytic ability, stability, and conductivity, as a noble metal, its high cost restricts the scale up production for DSSCs. To resolve this issue, many researchers are concentrating on CE catalytic materials, including carbon-based materials, metal sulfides, nitrides, polymers, and oxides, ${ }^{8-10}$ with a high conductivity, large specific surface areas, and a good catalytic ability ${ }^{6,7}$ Among these, metal sulfides with two-dimensional (2D) permeable channels possess the properties of ideal CE materials and are considered as promising electrode materials. ${ }^{\mathbf{1 1 2} 12}$ Lin et $a{ }^{13}{ }^{13}$ prepared a molybdenum disulfide CE for DSSCs and obtained a significant improvement in the power conversion efficiency. Moreover, we also successfully prepared a nickel disulfide CE with very promising results for DSSCs. ${ }^{13,14}$ Vanadium sulfide $\left(\mathrm{VS}_{2}\right)$ has been proven to be an ideal material platform due to its synergic properties of metallic nature brought about by the conducting $\mathrm{S}-\mathrm{V}-\mathrm{S}$ layers stacked up via weak van der Waals interlayer interactions, offering great potential as high-performance in-plane supercapacitor electrodes. ${ }^{\mathbf{1 5}}$ Therefore, it is interesting and significant to investigate

Henan Key Laboratory of Photovoltaic Materials and Laboratory of Low-Dimensional Materials Science, Henan University, Kaifeng 475004, China. E-mail: yuegentian@ henu.edu.cn; zhenghaiw@ustc.edu; Tel: +8637123880696 the potential applications of $\mathrm{VS}_{2}$ as a CE catalyst in DSSCs for low-cost and efficient photoelectric conversion efficiency.

Herein, we designed and synthesized $\mathrm{VS}_{2}$ nanofibres as a CE material via an in situ hydrothermal route for DSSCs, hoping that the $\mathrm{VS}_{2}$ nanofibres could promote the catalytic activity and improve the photovoltaic properties of the DSSC. The DSSC based on the $\mathrm{VS}_{2}$ nanofibre $\mathrm{CE}$ exhibited a high power conversion efficiency of $7.40 \%$. This study may broaden the potential applications of two-dimensional layered transition-metal dichalcogenides in the area of photoelectrochemistry.

\section{Experimental}

\subsection{Preparation of $\mathrm{VS}_{2} \mathrm{CES}$}

$\mathrm{VS}_{2}$ was prepared via modifying the procedure reported by Feng et $a l .{ }^{15} \mathrm{~A} 3 \mathrm{mmol}$ sodium orthovanadate and $15 \mathrm{mmol}$ thiourea were dissolved in $40 \mathrm{ml}$ distilled water; the mixture was then stirred for $1 \mathrm{~h}$ to form a homogeneous solution and transferred to a $50 \mathrm{ml}$ Teflon-lined autoclave. It was then heated in an oven at $140,160,180$, and $200{ }^{\circ} \mathrm{C}$ for $24 \mathrm{~h}$. The product was collected by centrifugation, washed at least 5 times with ethanol and distilled water, and dried in a vacuum oven at $80{ }^{\circ} \mathrm{C}$ for $12 \mathrm{~h}$. The slurry of the $\mathrm{VS}_{2} \mathrm{CE}$ was composed of nanofibre structure $\mathrm{VS}_{2}$, acetylene black, and polyvinylidene fluoride (weigh ratio = $8: 1: 1$ ), which were dissolved in $N$-methyl-2-pyrrolidinone. Then, the slurry was ultrasonicated for $30 \mathrm{~min}$ and was stirred for $12 \mathrm{~h}$. Subsequently, the as-prepared slurry was coated on the FTO substrates using a doctor blade method. The coated CEs were dried at $100{ }^{\circ} \mathrm{C}$ for $24 \mathrm{~h}$ in a vacuum oven.

\subsection{Fabrication of the DSSCs}

A $\mathrm{TiO}_{2}$ anode was prepared according to a previously reported procedure. ${ }^{16,17}$ The dye-sensitized $\mathrm{TiO}_{2}$ photoanode was 

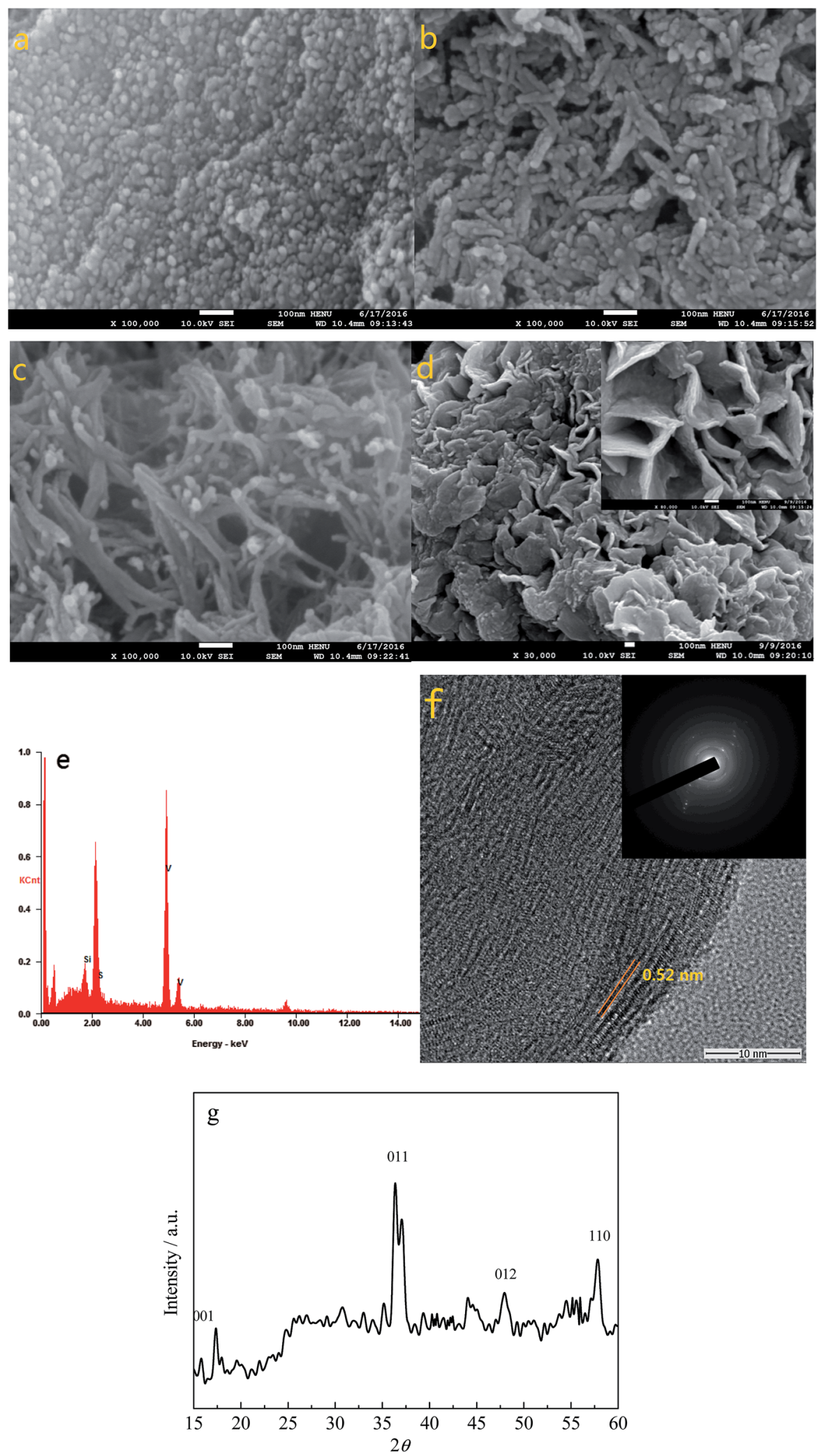

Fig. 1 The SEM images of $\mathrm{VS}_{2}$ obtained at (a) 140 (b) 160 , (c) 180 , and (d) $200{ }^{\circ} \mathrm{C}$; (e) the EDS spectrum of $\mathrm{VS}_{2}$; (f) $\mathrm{TEM}$ image of the $\mathrm{VS} 2$ obtained after the $180^{\circ} \mathrm{C}$ hydrothermal synthesis; (g) XRD pattern of the $\mathrm{VS}_{2}$ nanofibers.

constructed by immersing the $\mathrm{TiO}_{2}$ photoanode in a $0.3 \mathrm{mM}$ dye Z907 ethanol solution for $24 \mathrm{~h}$. Thus, a dye-sensitized $\mathrm{TiO}_{2}$ photoanode with a total thickness of 6-8 $\mu$ m was obtained. After this, the dye-sensitized $\mathrm{TiO}_{2}$ photoanode and the $\mathrm{CE}$ were clipped together and wrapped with the thermoplastic hot-melt Surlyn. The liquid electrolyte contained $0.05 \mathrm{M}$ of iodine, 
0.1 $\mathrm{M}$ of lithium iodide, $0.6 \mathrm{M}$ of tetrabutylammonium iodide, and $0.5 \mathrm{M}$ of 4-tert-butyl-pyridine in acetonitrile and was injected into the aperture between the two electrodes.

\subsection{Characterization}

The surface morphology of the sample was observed using a JSM-7001F field emission scanning electron microscope (SEM). Energy dispersive spectroscopy analysis (EDS) was carried out using a Bruker-ASX (Model Quan-Tax 200). A field emission transmission electron microscope (TEM; JEOL JEM$2100 \mathrm{~F}$, operated at $200 \mathrm{kV}$ with a point-to-point resolution of $0.19 \mathrm{~nm}$ ) was used to obtain information about the microstructures. The crystalline structures of the composites were investigated by glancing incidence X-ray diffractometer (X'Pert Pro, PANalytical B.V., the Netherlands). Electrochemical impendence spectroscopy (EIS) was carried out using a CHI660E (Shanghai Chenhua Device Company, China) electrochemical measurement system at a constant temperature of $25{ }^{\circ} \mathrm{C}$ in an ambient atmosphere under dark conditions, leaving an exposed area of $0.8 \mathrm{~cm}^{2}$. The frequency of the applied sinusoidal AC voltage signal was varied from $0.1 \mathrm{~Hz}$ to $10^{5} \mathrm{~Hz}$,

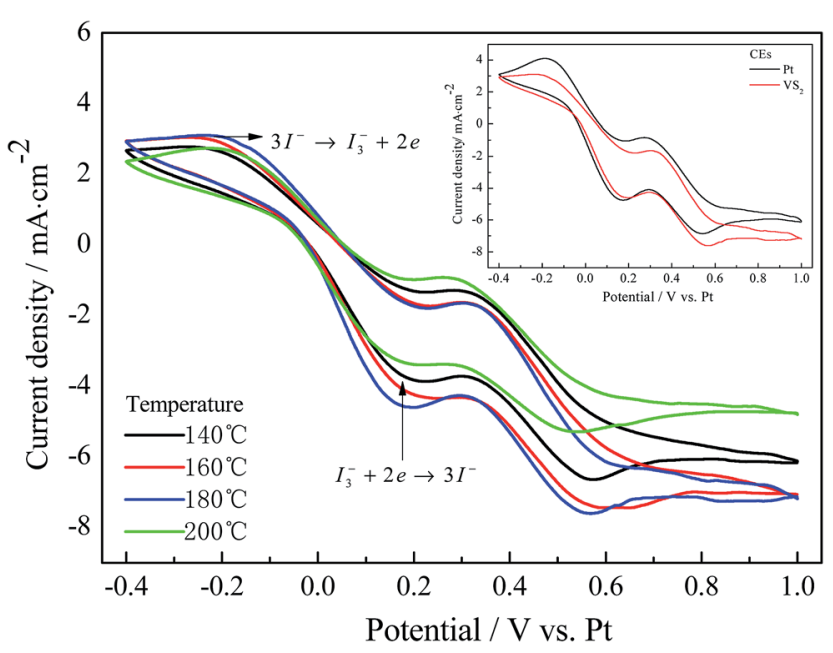

Fig. 2 Cyclic voltammograms for the Pt and VS 2 (prepared at $140{ }^{\circ} \mathrm{C}$ to $\left.200^{\circ} \mathrm{C}\right) \mathrm{CEs}$. and the corresponding amplitude was set at $5 \mathrm{mV}$ in all the cases.

The photovoltaic test of the DSSC with an exposed area of 0.2 $\mathrm{cm}^{2}$ was carried out by measuring photocurrent-photovoltage $(J-V)$ character curves under a white light irradiation of $100 \mathrm{~mW}$ $\mathrm{cm}^{-2}$ (AM $1.5 \mathrm{G}$ ) from a solar simulator (CEL-S500, Beijing China Education Au-light Co., Ltd) in an ambient atmosphere.

\section{Results and discussion}

Fig. 1a-d show the SEM images of $\mathrm{VS}_{2}$ obtained at 140, 160, 180, and $200{ }^{\circ} \mathrm{C}$, respectively. It can be seen that the size of the $\mathrm{VS}_{2}$ nanoparticles increased with the increasing temperature and the morphology also changed, from nanoparticles to nanofibers and nanosheets. This phenomenon indicates that a higher reaction temperature can promote the growth of $\mathrm{VS}_{2}$ crystals. The EDS patterns of $\mathrm{VS}_{2}$ prepared at $180^{\circ} \mathrm{C}$ are shown in Fig. 1e, in which the $\mathrm{V}$ and $\mathrm{S}$ elements with an almost $1: 1$ ratio can be detected, and the Si element originates from the Si substrate. Fig. If presents the TEM image of $\mathrm{VS}_{2}$, and the lattice spacing has been estimated to be $0.52 \mathrm{~nm}$, which is in accordance with the literature parameter for $\mathrm{VS}_{2}(0.573 \mathrm{~nm})$. To further identify the composition of the sample, Fig. $1 \mathrm{~g}$ shows the XRD pattern of the $\mathrm{VS}_{2}$ nanofibers obtained from the $180{ }^{\circ} \mathrm{C}$ hydrothermal synthesis. As can be seen, although there are some impurity peaks appearing in the sample, the (001), (011), (012), and (110) peaks of the $\mathrm{VS}_{2}$ all correspond to the JCPDS database card no. 89-1640. As a consequence, the results demonstrated that the $\mathrm{VS}_{2}$ has been successfully prepared via the facile hydrothermal synthesis at $180{ }^{\circ} \mathrm{C}$.

Fig. 2 presents the cyclic voltammograms of various CEs measured using a three-electrode system. In Fig. 2, the pair of peaks in the low potential area has a significant impact on the photovoltaic properties of the DSSCs between the two pairs of redox peaks. ${ }^{18}$ As observed from the inset of Fig. 2, the Pt and $\mathrm{VS}_{2}\left(180{ }^{\circ} \mathrm{C}\right.$ preparation) CEs have a similar cathodic peak current density $\left(J_{\mathrm{pc}}\right)$ and cathodic peak potential, indicating that the $\mathrm{VS}_{2} \mathrm{CE}$ is as good conductive and catalytic material as Pt. The $\mathrm{VS}_{2}$ CEs prepared at temperatures from 140 to $200{ }^{\circ} \mathrm{C}$ possess a similar cathodic peak potential, and the cathodic peak current density follows the order $\mathrm{VS}_{2}\left(180{ }^{\circ} \mathrm{C}\right)>\mathrm{VS}_{2}(160$
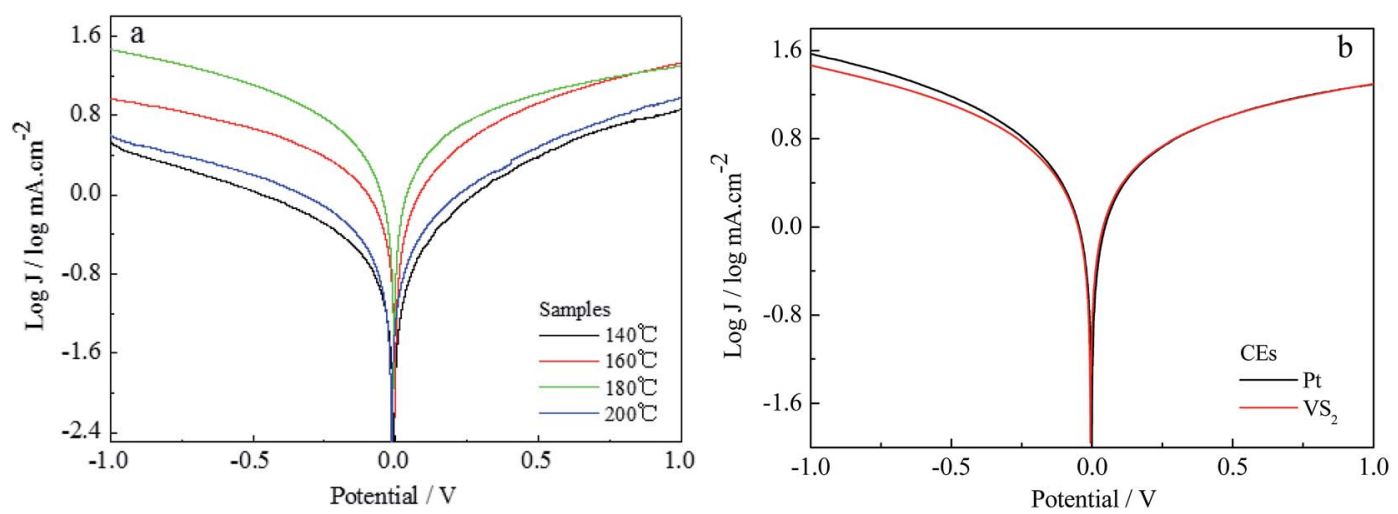

Fig. 3 Tafel curves for (a) various VS 2 CEs and (b) the Pt CE and the $\mathrm{VS}_{2}$ CE prepared at $180^{\circ} \mathrm{C}$. 
$\left.{ }^{\circ} \mathrm{C}\right)>\mathrm{VS}_{2}\left(140{ }^{\circ} \mathrm{C}\right)>\mathrm{VS}_{2}\left(200{ }^{\circ} \mathrm{C}\right) \mathrm{CEs}$, suggesting that the $\mathrm{VS}_{2} \mathrm{CE}$ prepared at $180{ }^{\circ} \mathrm{C}$ has a better catalytic activity and conductivity. This indicates that the electron transport was affected by the surface morphologies of the samples. $\mathrm{VS}_{2}$ nanofibers with a large specific surface area can vastly enhance the accessibility of the electrolyte to the electrode, thus improving interfacial charge transfer and increasing the number of active catalytic sites. ${ }^{19,20}$

Tafel curves for the $\mathrm{VS}_{2}$ CEs prepared at different temperature are shown in Fig. 3a. The exchange current density $\left(J_{0}\right)$, obtained as the intercept of the extrapolated linear region of the curve when the overpotential was zero, is positively correlated to the reduction capability of the CE materials in an $I / I_{3}{ }^{-}$electrolyte. The $\mathrm{VS}_{2}$ CEs prepared at temperatures from 140 to $200{ }^{\circ} \mathrm{C}$ exhibit the same change tendencies as for the CVs. Under the optimizing conditions, the $J_{0}$ of the $\mathrm{VS}_{2} \mathrm{CE}\left(180^{\circ} \mathrm{C}\right.$ preparation) is similar to that of the Pt CE, as shown in Fig. $3 \mathrm{~b}$. This is mainly because $\mathrm{VS}_{2}\left(180{ }^{\circ} \mathrm{C}\right.$ preparation) with nanofibre structure is better for electron transport than $\mathrm{VS}_{2}$ nanoparticles. Thus, this also indicates that the electrochemical catalytic activity of the $\mathrm{VS}_{2} \mathrm{CE}$ is significantly affected by the morphology.

Fig. 4 displays the electrochemical impedance spectroscopy (EIS) and equivalent circuit models of the Pt and the $\mathrm{VS}_{2}$ CEs synthesized at various temperatures, in which the first semicircle in the high frequency region denotes the charge-transfer resistance $\left(R_{\mathrm{ct}}\right)$ at the $\mathrm{CE} /$ electrolyte interface ${ }^{21,22}$ and the

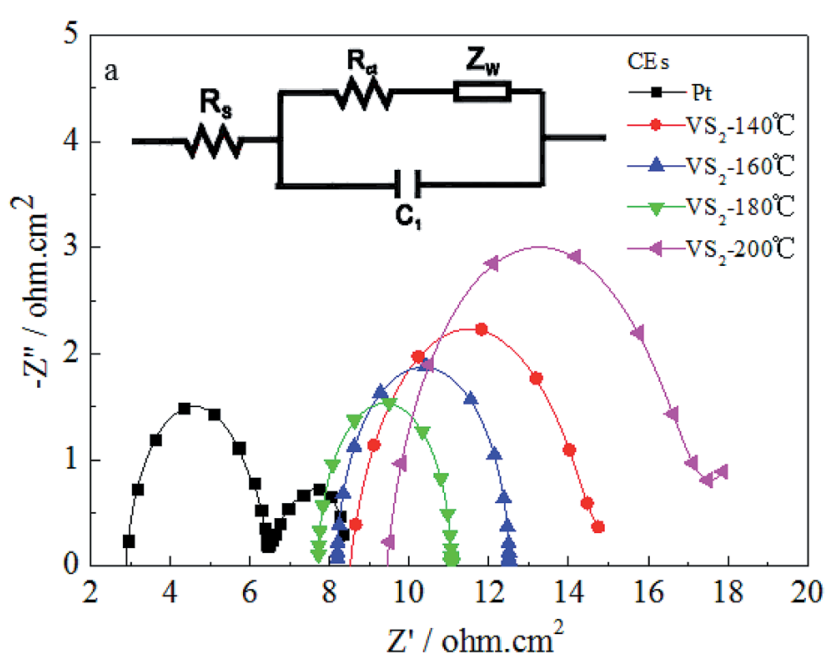

Fig. 4 EIS spectra for the Pt and VS 2 CEs. The inset (a) shows the equivalent circuit model used for fitting the resultant impedance spectra. corresponding EIS parameters are listed in Table 1. The smaller $R_{\text {ct }}$ exhibits a faster electron transfer from the CE to the electrolyte, which is a significant parameter for evaluating the performance of CEs. In Fig. 4, the values of $R_{\mathrm{ct}}$ for the $\mathrm{VS}_{2}$ CEs synthesized at 140,160, 180 and $200{ }^{\circ} \mathrm{C}$ are 6.437, 4.318, 3.360, and $8.435 \Omega \mathrm{cm}^{2}$, respectively; and the $R_{\mathrm{ct}}$ for the Pt CE is 3.432 $\Omega \mathrm{cm}^{2}$. The $R_{\mathrm{ct}}$ value for the $\mathrm{VS}_{2} \mathrm{CE}$ prepared at $180{ }^{\circ} \mathrm{C}$ is comparable to that of the Pt CE. The results are in agreement with the CVs and Tafel curves, and this can be attributed to the same reasons as for the CVs and Tafel curves.

Fig. 5 shows the photocurrent density-voltage curves for the DSSCs based on the Pt and $\mathrm{VS}_{2}\left(180^{\circ} \mathrm{C}\right.$ preparation) CEs under

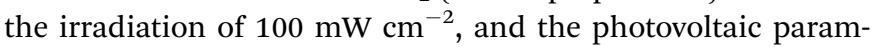
eters for the DSSCs are also summarized in Table 1. From Fig. 5, it can be observed that the DSSC based on the $\mathrm{VS}_{2} \mathrm{CE}$ synthesized at $180{ }^{\circ} \mathrm{C}$ achieved a power conversion efficiency (PCE) of $6.24 \%$, an open-circuit voltage $\left(V_{\text {oc }}\right)$ of $0.726 \mathrm{~V}$, a short-circuit current density $\left(J_{\mathrm{sc}}\right)$ of $13.65 \mathrm{~mA} \mathrm{~cm}{ }^{-2}$, and a fill factor (FF) of 0.63 , which are almost the same as those for the DSSC based on the Pt electrode $\left(\mathrm{PCE}=6.44 \%, V_{\mathrm{oc}}=0.717 \mathrm{~V}, J_{\mathrm{sc}}=14.03 \mathrm{~mA}\right.$ $\mathrm{cm}^{-2}$, and $\left.\mathrm{FF}=0.64\right)$. The DSSCs based on the $\mathrm{VS}_{2}$ CEs prepared at 140,160 and $200{ }^{\circ} \mathrm{C}$ have much lower PCEs than the DSSC with the $\mathrm{VS}_{2} \mathrm{CE}$ synthesized at $180{ }^{\circ} \mathrm{C}$. The positive effect in the performance of the DSSC based on the $\mathrm{VS}_{2}\left(180^{\circ} \mathrm{C}\right) \mathrm{CE}$ possibly results from the following aspects. First, the contact frequency between the $I / I_{3}{ }^{-}$redox couple in the electrolyte and the CE can be quickened because of the large specific surface area of

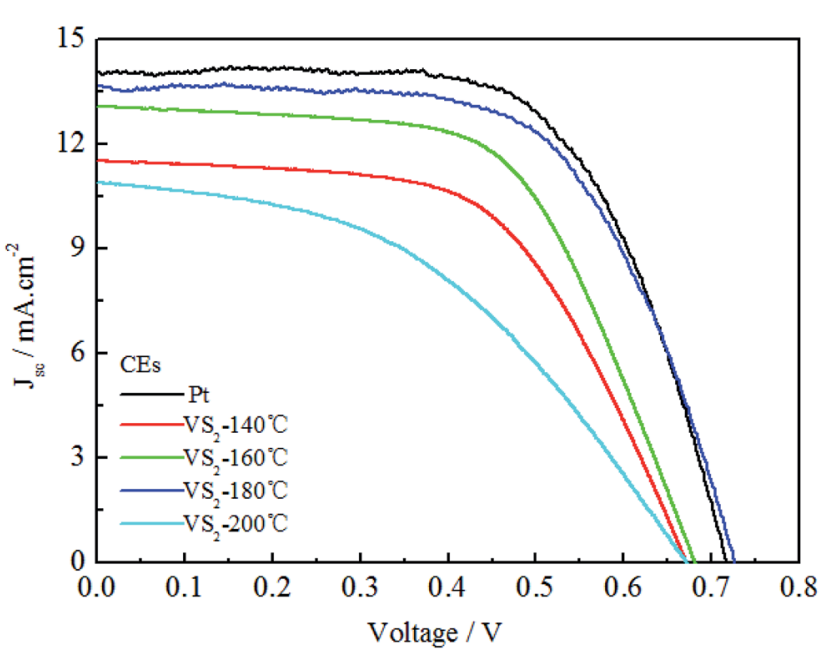

Fig. 5 Photocurrent density-voltage curves of the DSSCs based on Pt and various $\mathrm{VS}_{2} \mathrm{CEs}$.

Table 1 Electrochemical parameters for the Pt and VS ${ }_{2}$ CEs and the corresponding photocurrent-voltage parameters of the DSSCs

\begin{tabular}{llllll}
\hline Temp. $\left({ }^{\circ} \mathrm{C}\right)$ & $R_{\mathrm{ct}}\left(\Omega \mathrm{cm}^{2}\right)$ & $J_{\mathrm{pc}} \mid\left(\mathrm{mA} \mathrm{cm}{ }^{-2}\right)$ & $V_{\mathrm{oc}}(\mathrm{V})$ & $J_{\mathrm{sc}}\left(\mathrm{mA} \mathrm{cm}^{-2}\right)$ & \\
\hline 140 & 6.437 & 3.79 & 0.671 & 11.52 & \\
160 & 4.318 & 4.20 & 0.681 & 13.06 & 0.58 \\
180 & 3.360 & 4.55 & 0.726 & 13.65 & 0.60 \\
200 & 8.435 & 3.33 & 0.672 & 10.89 & 0.63 \\
Pt & 3.432 & 4.65 & 0.717 & 14.03 & 0.46 \\
\end{tabular}


the $\mathrm{VS}_{2}$ nanofibers, such that to provide a good reaction speed for the reduction of $\mathrm{I}_{3}{ }^{-}$to $\Gamma$. In addition, the $\mathrm{VS}_{2}$ nanofibers have synergic advantages of a high conductivity and $2 \mathrm{D}$ permeable channels guarantee the rapid transmission of electrons, thereby showing efficient PCEs for the DSSCs based on the $\mathrm{VS}_{2} \mathrm{CE}$. In addition, it has been reported in previous studies that $\mathrm{VS}_{2}$ was successfully assembled for constructing the electrodes of in-plane supercapacitors. ${ }^{23,24}$ To the best of our knowledge, it is the first time that $\mathrm{VS}_{2}$ has been reported as a $\mathrm{CE}$ material for DSSCs.

\section{Conclusion}

$\mathrm{VS}_{2}$ nanofibers were prepared via in situ hydrothermal techniques and were employed as a CE in the Pt-free DSSCs for the first time. The sizes of $\mathrm{VS}_{2}$ increase and the morphology is also affected with the increasing temperature, whereby nanoparticles were observed to changed into nanofibers and even nanosheets. Extensive electrochemical and photoelectric chemical experiments indicate that the $\mathrm{VS}_{2}$ nanofibers prepared at $180{ }^{\circ} \mathrm{C}$ have the synergic advantages of high conductivity, large specific surface area, and 2D permeable channels and provide the most excellent catalytic activity for the reduction of triiodide compared to $\mathrm{VS}_{2}$ prepared at 140,160 , and $200{ }^{\circ} \mathrm{C}$. Under the optimum conditions, the PCE of the DSSC based on the $\mathrm{VS}_{2}$ nanofiber CE $(6.24 \%)$ is as high as that of the DSSC based on the Pt electrode (6.44\%). This study offers a new and effective material substitution to $\mathrm{Pt}$, which will broaden the application field of $2 \mathrm{D}$ sulfides.

\section{Conflict of interest}

The authors declare that they have no competing interests.

\section{Acknowledgements}

The authors are very grateful for the joint support by the National Natural Science Foundation of China (No. U1504624). This work was also supported by the China Postdoctoral Science Foundation Funded Project (No. 2015M572102).

\section{References}

1 B. O'Regan and M. Grätzel, Nature, 1991, 353, 737-740.

2 A. Yella, H. W. Lee, H. N. Tsao, C. Y. Yi, A. K. Chandiran, M. K. Nazeeruddin, E. W. G. Diau, C. Y. Yeh, S. M. Zakeeruddin and M. Grätzel, Science, 2011, 334, 629-634. 3 A. Hagfeldt, G. Boschloo, L. Sun, L. Kloo and H. Pettersson, Chem. Rev., 2010, 110, 6595-6663.

4 S. Mathew, A. Yella, P. Gao, R. Humphry-Baker, B. F. E. Curchod, N. Ashari-Astani, I. Tavernelli,
U. Rothlisberger, M. K. Nazeeruddin and M. Grätzel, Nat. Chem., 2014, 6, 242-247.

5 J. H. Wu, Z. Lan, J. M. Lin, M. L. Huang, Y. F. Huang, L. Q. Fan and G. G. Luo, Chem. Rev., 2015, 115, 2136-2173.

6 Y. J. Li, Q. W. Tang, L. M. Yu, X. F. Yan and L. Dong, J. Power Sources, 2016, 305, 217-224.

7 G. T. Yue, X. P. Ma, W. F. Zhang, F. M. Li, J. H. Wu and G. Q. Li, Nanoscale Res. Lett., 2015, 10, 1-9.

8 Z. Q. Li, F. Gong, G. Zhou and Z. S. Wang, J. Phys. Chem. C, 2013, 117, 6561-6566.

9 H. C. Sun, D. Qin, S. Q. Huang, X. Z. Guo, D. M. Li, Y. H. Luo and Q. B. Meng, Energy Environ. Sci., 2011, 4, 2630-2637.

10 G. T. Yue, P. Li, F. M. Li and C. Chen, RSC Adv., 2016, 6, 61278-61283.

11 M. Mulazzi, A. Chainani, N. Katayama, R. Eguchi, M. Matsunami, H. Ohashi, Y. Senba, M. Nohara, M. Uchida, H. Takagi and S. Shin, Phys. Rev. B: Condens. Matter Mater. Phys., 2010, 82, 075130.

12 K. S. Kim, Y. Zhao, H. Jang, S. Y. Lee, J. M. Kim, K. S. Kim, J. H. Ahn, P. Kim, J. Y. Choi and B. H. Hong, Nature, 2009, 457, 706-710.

13 J. Y. Lin, A. L. Su, C. Y. Chang, K. C. Hung and T. W. Lin, ChemElectroChem, 2015, 2, 720-725.

14 G. T. Yue, F. R. Tan, F. M. Li, C. Chen, W. F. Zhang, J. H. Wu and Q. H. Li, Electrochim. Acta, 2014, 149, 117-125.

15 J. Feng, X. Sun, C. Z. Wu, L. L. Peng, C. W. Lin, S. L. Hu, J. L. Yang and Y. Xie, J. Am. Chem. Soc., 2011, 133, 1783217838.

16 G. T. Yue, J. H. Wu, Y. M. Xiao, M. L. Huang, J. M. Lin and J.-Y. Lin, J. Mater. Chem. A, 2013, 1, 1495-1501.

17 Z.-Q. Li, Y.-P. Que, L.-E. Mo, W.-C. Chen, Y. Ding, Y.-M. Ma, L. Jiang, L.-H. Hu and S.-Y. Dai, ACS Appl. Mater. Interfaces, 2015, 7, 10928-10934.

18 G. T. Yue, J. H. Wu, J.-Y. Lin, Y. M. Xiao, J. M. Lin, M. L. Huang and Z. Lan, Carbon, 2013, 55, 1-9.

19 C.-T. Li, Y.-L. Tsai and K.-C. Ho, ACS Appl. Mater. Interfaces, 2016, 8, 7037-7046.

20 H. Sun, J. Deng, L. Qiu, X. Fang and H. Peng, Energy Environ. Sci., 2015, 8, 1139-1159.

21 Y. Xiao, G. Han, Y. Li, M. Li and Y. Chang, J. Mater. Chem. A, 2014, 2, 3452-3460.

22 G. Yue, J. Wu, Y. Xiao, J. Lin, M. Huang and Z. Lan, J. Phys. Chem. C, 2012, 116, 18057-18063.

23 D. Pech, M. Brunet, H. Durou, P. Huang, V. Mochalin, Y. Gogotsi, P. L. Taberna and P. Simon, Nat. Nanotechnol., 2010, 5, 651-654.

24 J. J. Yoo, K. Balakrishnan, J. Huang, V. Meunier, B. G. Sumpter, A. Srivastava, M. Conway, A. L. Mohana Reddy, J. Yu, R. Vajtai and P. M. Ajayan, Nano Lett., 2011, 11, 1423-1427. 